\title{
Reponses and sensitivities of maize phenology to climate change from 1981 to 2009 in Henan Province, China
}

\author{
LIU Yujie ${ }^{1}$, QIN Ya ${ }^{1,2}$, GE Quansheng ${ }^{1}$, DAI Junhu ${ }^{1}$, CHEN Qiaomin ${ }^{1,3}$
}

1. Key Laboratory of Land Surface Pattern and Simulation, Institute of Geographic Sciences and Natural Resources Research, CAS, Beijing 100101, China;

2. Xi'an University of Science and Technology, College of Surveying and Mapping Science and Technology, Xi'an 710054, China;

3. University of Chinese Academy of Sciences, Beijing 100049, China

\begin{abstract}
With the global warming, crop phenological shifts in responses to climate change have become a hot research topic. Based on the long-term observed agro-meteorological phenological data (1981-2009) and meteorological data, we quantitatively analyzed temporal and spatial shifts in maize phenology and their sensitivities to key climate factors change using climate tendency rate and sensitivity analysis methods. Results indicated that the sowing date was significantly delayed and the delay tendency rate was $9.0 \mathrm{~d} \cdot 10 \mathrm{a}^{-1}$. But the stages from emergence to maturity occurred earlier $\left(0.1 \mathrm{~d} \cdot 10 \mathrm{a}^{-1}<\theta<1.7 \mathrm{~d} \cdot 10 \mathrm{a}^{-1}, \theta\right.$ is the change slope of maize phenology). The length of vegetative period (VPL) (from emergence to tasseling) was shortened by $0.9 \mathrm{~d} \cdot 10 \mathrm{a}^{-1}$, while the length of generative period (GPL) (from tasseling to maturity) was lengthened by $1.7 \mathrm{~d} \cdot 10 \mathrm{a}^{-1}$. The growing season length (GSL) (from emergence to maturity) was lengthened by $0.4 \mathrm{~d} \cdot 10 \mathrm{a}^{-1}$. Correlation analysis indicated that maize phenology was significantly correlated with average temperature, precipitation, sunshine duration and growing degree days (GDD) $(p<0.01)$. Average temperature had significant negative correlation relationship, while precipitation, sunshine duration and growing degree days had significant positive correlations with maize phenology. Sensitivity analysis indicated that maize phenology showed different responses to variations in key climate factors, especially at different sites. The conclusions of this research could provide scientific supports for agricultural adaptation to climate change to address the global food security issue.
\end{abstract}

Keywords: climate change; maize; phenology; trend analysis; sensitivity

Received: 2016-11-15 Accepted: 2017-01-16

Foundation: National Natural Science Foundation of China, No.41671037, No.41301091; The National Key Research and Development Program of China, No.2016YFA0602402; The Youth Innovation Promotion Association of CAS, No.2016049

Author: Liu Yujie, PhD and Associate Professor, specialized in climate change. E-mail: liuyujie@igsnrr.ac.cn 


\section{Introduction}

Phenology is the study of periodic plant and animal life cycle events and how these are influenced by seasonal and interannual variations in climate, as well as habitat factors (Zhu and Wan, 1973). As the phenology will shift with the environmental changes and therefore it can be used as an important biological indicator to reflect the responses of terrestrial systems to climate change (He et al., 2015). According to IPCC 5th Assessment Report, the global average temperature has increased by $0.85^{\circ} \mathrm{C}$ over the past 100 years (IPCC, 2013). Under the background of global warming, the studies of the responses of phenology to climate change have become an important international issue.

Many studies have shown that shifts in plant phenology were correlated with increasing temperature (Schleip et al., 2009; Wu and Liu, 2013; Wittich and Liedtke, 2015). For instance, Wang et al. (2015) studied the influence of temperature rising and frost in wheat flowering period in eastern Australia, which suggested that farmers could choose longer growing-season cultivars to offset the negative effects of increasing temperature in the future. Other studies also paid attention to precipitation and other climate factors. For instance, Wang et al. (2016) investigated the influences of average temperature and precipitation on the growing season of maize and soybean in the East Greater Hinggan Mountains during the last 29 years. Ji et al. (2012) found that precipitation during the growing season of maize in Northeast China decreased starting from 1991, and the accumulated temperature $\left(\geqslant 10^{\circ} \mathrm{C}\right)$ zone extended northward 200 to $300 \mathrm{~km}$ and eastward 50 to $150 \mathrm{~km}$ since 1971 . Ren and Yin (2013) focused on single climate factor during the crop growing season in upstream of the Hanjiang River, and found that late spring chilling would seriously affect the production of rice, wheat and fruit trees. Some researchers have also studied the impacts of tropical climate change on the growth and phenological phases of Jerusalem artichoke, and found that low temperature and a short-wave light were good for Jerusalem artichoke tuber growth and development (Puangbut et al., 2015). Oteros et al. (2015) used a general linear hybrid model to examine the influences of temperature change on each phenological parameter in different species of Spanish cereal crops. The results showed that changes of phenology affected crop yield but proper human intervention would reduce these negative effects.

Although a large number of studies have been carried out, most of them only focused on a single climate factor change influences such as temperature or precipitation, on crop phenology. Actually, compared with natural plants, crop phenology is influenced by the joint effects of climate, hydrology, soil condition and the management measures. Currently, quantitative researches on comprehensive changes of multiple climate factors on crop phenology were still insufficient (Tao et al., 2014; He et al., 2015). Therefore, based on the long sequence of phenological observation data from 1981 to 2009, this study analyzed the temporal and spatial shifts of maize phenology and their sensitivities to key climate factors in Henan Province. The mechanism of climate change impacts on key phenological trends for maize was also discussed.

\section{Data and methods}

\subsection{Study area}

Henan, one of the major grain production provinces in China, is located between $31^{\circ} 23^{\prime}-$ 
$36^{\circ} 22^{\prime} \mathrm{N}$ and $110^{\circ} 21^{\prime}-116^{\circ} 39^{\prime} \mathrm{E}$. The annual average temperature is $13-15^{\circ} \mathrm{C}$, varying from $-1.57^{\circ} \mathrm{C}$ to $3.54^{\circ} \mathrm{C}$ in January and $24^{\circ} \mathrm{C}$ to $28^{\circ} \mathrm{C}$ in July. The annual frost-free period is 180 to 240 days from north to south. The annual precipitation is approximately 550 to $1100 \mathrm{~mm}$, and concentrates in the southern and western regions. Half of the annual precipitation concentrates in summer, often with heavy rains. The sunshine duration is 1800 to 2100 hours per year. The typical planting system is winter wheat and summer maize rotation, which could be representative of agricultural production in the North China Plain.

\subsection{Data}

Agro-meteorological stations selected for analysis must meet the following criterions: (1) have long historical observation records of maize phenology; (2) have matched climate observed data, which can be used to perform correlation analysis; (3) have field management records, such as cultivars and irrigation and fertilizer practices; (4) highlight local agricultural production. Based on the above requirements, six sites were selected, namely, Lushi (LS), Nanyang (NY), Ruzhou (RZ), Shangqiu (SQ), Xinxiang (XX), and Zhengzhou (ZZ) for the whole study area. The maize phenological data from 1981 to 2009 include sowing date (SOD), emergence date (EMD), trefoil date (TRD), seven leaf date (SLD), jointing date (JOD), tasseling date (TAD), flowering date (FLD), silking date (SID), milk ripening date (MRD) and maturity date (MAD). Corresponding meteorological observation data from 1981 to 2009 were also collected including maximum temperature, minimum temperature, average temperature, precipitation and sunshine duration. The locations and average annual changes for main climate factors at each station are presented in Figure 1 and Table 1, respectively.

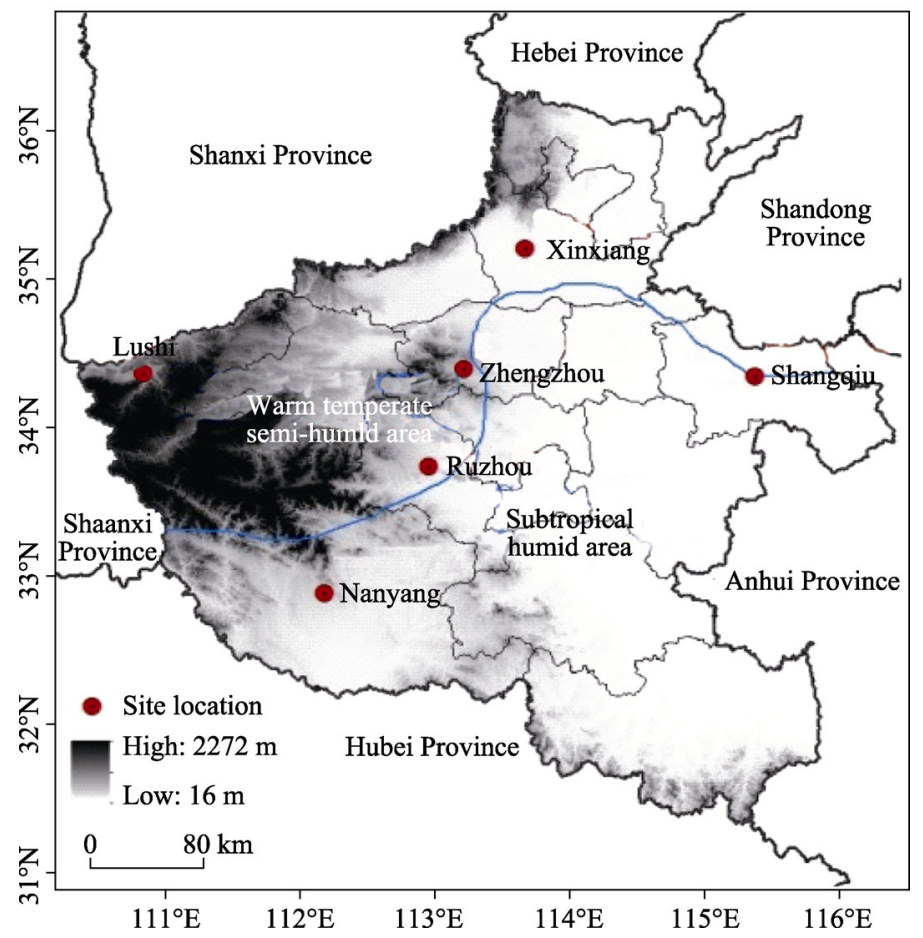

Figure 1 Location of the study area and selected sites in Henan Province 
Table 1 Geographical information and average annual climate changes during maize growing season (mean value \pm SD) of each site in Henan Province

\begin{tabular}{cccccccc}
\hline Station & $\begin{array}{c}\text { Longitude } \\
\left({ }^{\circ} \mathrm{E}\right)\end{array}$ & $\begin{array}{c}\text { Latitude } \\
\left({ }^{\circ} \mathrm{N}\right)\end{array}$ & $\begin{array}{c}\text { Altitude } \\
(\mathrm{m})\end{array}$ & $\begin{array}{c}\text { Growing season } \\
\text { length }(\mathrm{d})\end{array}$ & $\begin{array}{c}T_{\text {mean }} \\
\left({ }^{\circ} \mathrm{C}\right)\end{array}$ & $\begin{array}{c}\text { Precipitation } \\
(\mathrm{mm})\end{array}$ & $\begin{array}{c}\text { Sunshine } \\
\text { duration }(\mathrm{h})\end{array}$ \\
\hline LS & 111.02 & 34.00 & 568.80 & $85.36 \pm 16.93$ & $23.32 \pm 2.88$ & $416.05 \pm 5.13$ & $514.54 \pm 4.15$ \\
$\mathrm{NY}$ & 112.58 & 33.17 & 129.2 & $97.67 \pm 8.40$ & $25.93 \pm 2.59$ & $431.39 \pm 13.53$ & $496.64 \pm 4.12$ \\
$\mathrm{RZ}$ & 112.83 & 34.18 & 212.9 & $93.29 \pm 6.32$ & $25.90 \pm 2.72$ & $392.68 \pm 12.83$ & $510.27 \pm 4.00$ \\
$\mathrm{SQ}$ & 115.67 & 34.45 & 50.10 & $90.97 \pm 6.09$ & $25.82 \pm 2.68$ & $518.60 \pm 14.54$ & $551.74 \pm 4.28$ \\
$\mathrm{XX}$ & 113.82 & 35.17 & 79.00 & $92.69 \pm 7.41$ & $25.97 \pm 2.58$ & $335.11 \pm 11.83$ & $586.69 \pm 4.05$ \\
$\mathrm{ZZ}$ & 113.67 & 34.82 & 80.80 & $90.07 \pm 4.31$ & $26.08 \pm 2.65$ & $388.65 \pm 13.09$ & $485.72 \pm 3.98$ \\
\hline
\end{tabular}

\subsection{Methods}

\subsubsection{Trend analysis}

Trend analysis was used to analyze the temporal variations in maize phenology at each site from 1981 to 2009. This method can quantitatively assess the overall tendency of each trait during the whole study period (Guo et al., 2010; Ma et al., 2006). The formula is shown below:

$$
\theta_{i}=\frac{n \times \sum_{j=1}^{n}\left(j \times p_{i, j}\right)-\sum_{j=1}^{n} j \times \sum_{j=1}^{n} p_{i, j}}{n \times \sum_{j=1}^{n} j^{2}-\left(\sum_{j=1}^{n} j\right)^{2}}
$$

where $n$ is the number of years, $P_{i, j}$ is the value of variable $i$ in year $j$, and $\theta_{i}$ is the change slope of variable $i$. If $\theta_{i}>0$, the maize phenological period was delayed or lengthened, otherwise it was advanced or shortened.

The $t$-test was used to test the significance of the changing trend.

\subsubsection{Sensitivity analysis}

The sensitivity of the phenological change refers to the days that maize phenological period changes as the climate factors changes one unit. Generally, linear regression is used to represent the relationship between phenology and the climate factors:

$$
y=a+\frac{\sum_{i=1}^{n}\left(x_{i}-\bar{x}\right)\left(y_{i}-\bar{y}\right)}{\sum_{i=1}^{n}\left(x_{i}-\bar{x}\right)^{2}} * x=a+b x
$$

where $x$ represents the average value of climate factors, and $y$ is the maize phenology. The sensitivity coefficient can be expressed as:

$$
S e=\frac{d y}{d x}=b
$$

The regression coefficient $b$ can be calculated using the least squares method (LSM). The formula is as follows:

$$
S e=\frac{d y}{d x}=b=\frac{\sum_{i=1}^{n}\left(x_{i}-\bar{x}\right)\left(y_{i}-\bar{y}\right)}{\sum_{i=1}^{n}\left(x_{i}-\bar{x}\right)^{2}}=\frac{\sum_{i=1}^{n}\left(x_{i}-\bar{x}\right)\left(y_{i}-\bar{y}\right)}{\sqrt{\sum_{i=1}^{n}\left(x_{i}-\bar{x}\right)^{2}\left(y_{i}-\bar{y}\right)^{2}}} * \frac{\frac{1}{n} \sqrt{\sum_{i=1}^{n}\left(y_{i}-\bar{y}\right)^{2}}}{\frac{1}{n} \sqrt{\left(x_{i}-\bar{x}\right)^{2}}}=r \frac{S D_{p h e}}{S D_{\text {tem }}}
$$


where $r$ is the Pearson correlation coefficient between $x$ and $y, S D_{\text {phe }}$ is the standard deviation (SD) of the phenological time series, and $S D_{\text {tem }}$ is the time series data standard deviation of climate factor. The $S e$ is significant if the correlation coefficients $(r)$ of $y$ and $x$ are obvious.

\subsubsection{Growing degree days}

Generally, growing degree days (GDD) is an index used to analyze the quantity of heat that crop growth requires. In this study, GDD refers to the accumulated average daily temperature higher than $10^{\circ} \mathrm{C}$. The formula is expressed as following (McMaster and Wilhelm, 1997):

$$
G D D=\sum_{0}^{n}\left[\frac{T_{\max }+T_{\min }}{2}\right]-T_{\text {base }}
$$

where $T_{\max }$ is the daily maximum temperature, $T_{\min }$ is the daily minimum temperature, and $T_{\text {base }}$ is the biological lower limit temperature in maize growing season $\left(10^{\circ} \mathrm{C}\right.$ ) (Hou et al., 2014).

\section{Results analysis}

\subsection{Trends of key climate factors}

Over the past 29 years, trend of average temperature in Henan was $0.2^{\circ} \mathrm{C} \cdot 10 \mathrm{a}^{-1}$ during the maize growing season, showing an increasing trend (Table 2). As the altitude of LS was the highest of all the sites, the maximum temperature during growing season was lower than that of the other sites (Figure 2a). The warming tendency rate at LS was the highest of all the six sites (Table 2). It can be found that the tendency rate grew higher with the increase of the altitude. The average precipitation showed an increasing trend in the maize growing season, and the tendency rate was $30.7 \mathrm{~mm} \cdot 10 \mathrm{a}^{-1}$. The changing rate at RZ, XX and ZZ was higher than that of the other sites and reached a significance level. The annual fluctuation range of precipitation at SQ was the largest (Figure 2b). The sunshine duration of most sites decreased with a rate of $28.1 \mathrm{~h} \cdot 10 \mathrm{a}^{-1}$ except RZ, which increased by $14.5 \mathrm{~h} \cdot 10 \mathrm{a}^{-1}$. The sunshine duration of LS in most of the years was higher than the 29-year median value (1981-2009) (Figure 2c). The average GDD of growing season increased by $51.6^{\circ} \mathrm{C} \cdot 10 \mathrm{a}^{-1}$, but the tendency varied at each site. GDD at SQ, XX and ZZ increased while the other three sites showed a decreasing tendency (Table 2).

\subsection{Phenological changes}

Overall, the maize phenology was advanced during the whole growing season (Table 3 and Figure 3). EMD and TRD of most sites were advanced by $0.8 \mathrm{~d} \cdot 10 \mathrm{a}^{-1}$ and $0.1 \mathrm{~d} \cdot 10 \mathrm{a}^{-1}$ respectively. The changes of SLD and MAD were not significant. SLD, JOD, TAD, FLD, SID and MRD were advanced by $0.2 \mathrm{~d} \cdot 10 \mathrm{a}^{-1}, 1.3 \mathrm{~d} \cdot 10 \mathrm{a}^{-1}, 1.7 \mathrm{~d} \cdot 10 \mathrm{a}^{-1}, 1.3 \mathrm{~d} \cdot 10 \mathrm{a}^{-1}, 0.8 \mathrm{~d} \cdot 10 \mathrm{a}^{-1}$ and $1.6 \mathrm{~d} \cdot 10 \mathrm{a}^{-1}$ respectively. Among them, the TAD, SID and MRD presented significant changing trends. The SOD of each site presented a trend of delay, averaging $9.0 \mathrm{~d} \cdot 10 \mathrm{a}^{-1}$ for the whole study area. But the extent of the changes varied at different sites.

We further analyzed the changing differences among sites. The average MAD of the 

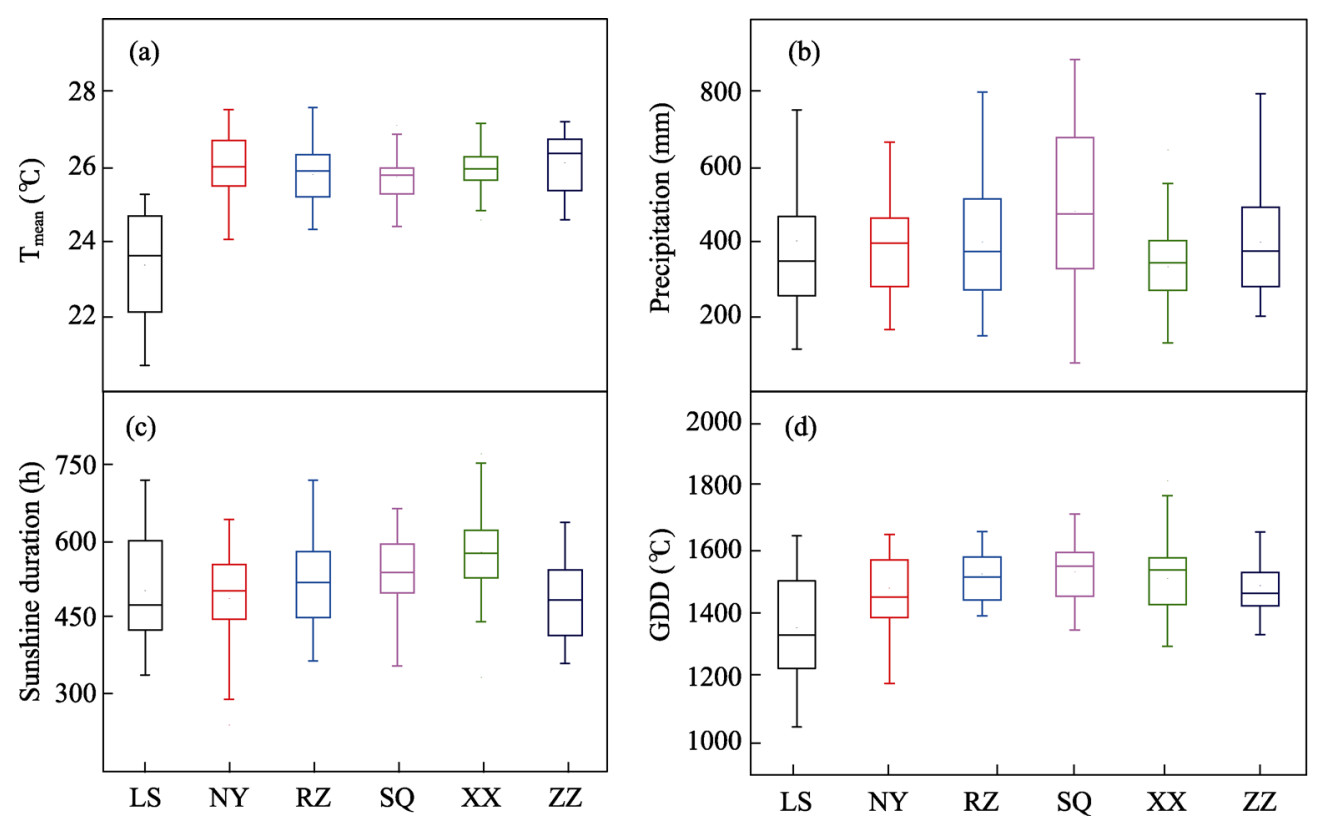

Figure 2 Changes of key climate factors during the maize growing season (1981-2009) at different sites in Henan Province (Different climate factors in growing season of the same site also showed different changes. At LS and NY, average temperature and precipitation during maize growing season increased while sunshine duration and GDD decreased. The average temperature, precipitation and GDD during the maize growing season decreased at SQ, XX and ZZ. RZ was characterized by increasing in the average temperature, precipitation and sunshine duration but decreasing in GDD.)

Table 2 Climate change tendency rates at different sites in Henan Province ( + and - indicated that the climate factor increased or decreased, respectively. ${ }^{* *}$ and $*$ indicated significance levels at $1 \%$ and $5 \%$ respectively. The bellows are same)

\begin{tabular}{lccccccc}
\hline \multicolumn{1}{c}{ Climate factor } & LS & NY & RZ & SQ & XX & ZZ & Study area \\
\hline$T_{\text {mean }}\left({ }^{\circ} \mathrm{C} \cdot 10 \mathrm{a}^{-1}\right)$ & $0.7^{*}$ & 0.2 & 0.1 & 0.1 & 0.1 & $0.3^{*}$ & 0.2 \\
Precipitation $\left(\mathrm{mm} \cdot 10 \mathrm{a}^{-1}\right)$ & 15.1 & 25.8 & $96.8^{* *}$ & 8.3 & $33.0^{* *}$ & $78.6^{*}$ & 30.7 \\
Sunshine duration $\left(\mathrm{h} \cdot 10 \mathrm{a}^{-1}\right)$ & $-63.1^{*}$ & -29.1 & 14.5 & $-42.5^{*}$ & -31.2 & -20.1 & $-28.1^{* *}$ \\
GDD $\left({ }^{\circ} \mathrm{C} \cdot 10 \mathrm{a}^{-1}\right)$ & -85.8 & $-66.6^{*}$ & $-76.8^{* *}$ & $55.4^{* *}$ & $89.3^{* *}$ & $61.5^{* *}$ & $51.6^{* *}$ \\
\hline
\end{tabular}

whole region was advanced by $0.4 \mathrm{~d} \cdot 10 \mathrm{a}^{-1}$. But MAD of maize at most sites showed a delayed trend, with XX being delayed the most and reaching the significance level of $p<0.01$. However, the MAD was advanced at LS and ZZ. The MAD changing trend at LS was significant. It can also be found that most maize phenological stages at LS were advanced except for SOD.

The vegetative period length (VPL) refers to the number of days from EMD to TAD during maize growing. As shown in Figure 3, the maize VPL showed a decreasing trend at most sites. At LS, NY, RZ, SQ and XX, it was shortened by $5.5 \mathrm{~d} \cdot 10 \mathrm{a}^{-1}, 1.1 \mathrm{~d} \cdot 10 \mathrm{a}^{-1}, 0.5 \mathrm{~d} \cdot 10 \mathrm{a}^{-1}$, $0.4 \mathrm{~d} \cdot 10 \mathrm{a}^{-1}$ and $1.8 \mathrm{~d} \cdot 10 \mathrm{a}^{-1}$ respectively, while it was lengthened by $1.4 \mathrm{~d} \cdot 10 \mathrm{a}^{-1}$ at $\mathrm{ZZ}$. The VPL changing trend at LS was significant at $p<0.05$ level. Averagely, the VPL of maize in Henan was shortened by $0.9 \mathrm{~d} \cdot 10 \mathrm{a}^{-1}$. The generative period length (GPL) is the number of days from TAD to MAD. In Henan, the maize GPL was prolonged by $1.7 \mathrm{~d} \cdot 10 \mathrm{a}^{-1}$ from 1981 to 2009 . It was prolonged by $1.9 \mathrm{~d} \cdot 10 \mathrm{a}^{-1}, 3.1 \mathrm{~d} \cdot 10 \mathrm{a}^{-1}, 1.7 \mathrm{~d} \cdot 10 \mathrm{a}^{-1}$ and $5.0 \mathrm{~d} \cdot 10 \mathrm{a}^{-1}$ at $\mathrm{NY}, \mathrm{RZ}$, SQ and XX, respectively. The changing trend at XX reached the significance level of $p<0.01$. 
But the GPL of LS was shortened by $0.9 \mathrm{~d} \cdot 10 \mathrm{a}^{-1}$ (Figure 3a). Generally, the growing season length (GSL: the number of days from EMD to MAD) of maize was prolonged by 0.4 $\mathrm{d} \cdot 10 \mathrm{a}^{-1}$ averagely. It was extended by $0.8 \mathrm{~d} \cdot 10 \mathrm{a}^{-1}, 2.6 \mathrm{~d} \cdot 10 \mathrm{a}^{-1}, 1.4 \mathrm{~d} \cdot 10 \mathrm{a}^{-1}, 3.2 \mathrm{~d} \cdot 10 \mathrm{a}^{-1}$ and $0.9 \mathrm{~d} \cdot 10 \mathrm{a}^{-1}$ at NY, RZ, SQ, XX and ZZ, respectively, but the GSL of LS was shortened by $9.8 \mathrm{~d} \cdot 10 \mathrm{a}^{-1}$.

Table 3 The trends of the changes of maize phenology at selected stations in Henan Province ( + and - in the table showed delay and advance of the phenological stages respectively. The unit is $\mathrm{d} \cdot 10 \mathrm{a}^{-1}$ )

\begin{tabular}{ccccccccccc}
\hline Station & SOD & EMD & TRD & SLD & JOD & TAD & FLD & SID & MRD & MAD \\
\hline LS & 10.0 & -3.1 & -0.7 & $-4.0^{*}$ & -3.7 & $-6.7^{* *}$ & -9.6 & -2.7 & $-11.0^{* *}$ & $-12.9^{*}$ \\
NY & $11.9^{* *}$ & 0.3 & -0.4 & -1.1 & 0.5 & -0.8 & -1.1 & -1.6 & -1.6 & 1.1 \\
RZ & 5.9 & -1.4 & 0.7 & 1.0 & -0.5 & -1.4 & -0.4 & -0.4 & $4.4^{* *}$ & 1.7 \\
SQ & $10.2^{*}$ & -0.1 & -0.1 & 0.3 & -1.3 & -0.5 & -0.8 & 0.7 & 1.0 & 1.2 \\
XX & $11.0^{* *}$ & 1.1 & 2.3 & $3.1^{*}$ & -3.0 & -0.6 & 0.9 & 1.0 & 1.2 & $4.3^{* *}$ \\
ZZ & 5.3 & -1.4 & -1.2 & 0.07 & 0.07 & 0.06 & -0.04 & -0.4 & -3.2 & -0.5 \\
Study area & $9.0^{* *}$ & -0.8 & -0.1 & -0.2 & -1.3 & $-1.7^{*}$ & -1.3 & $-0.8^{*}$ & $-1.6^{*}$ & -0.4 \\
\hline
\end{tabular}

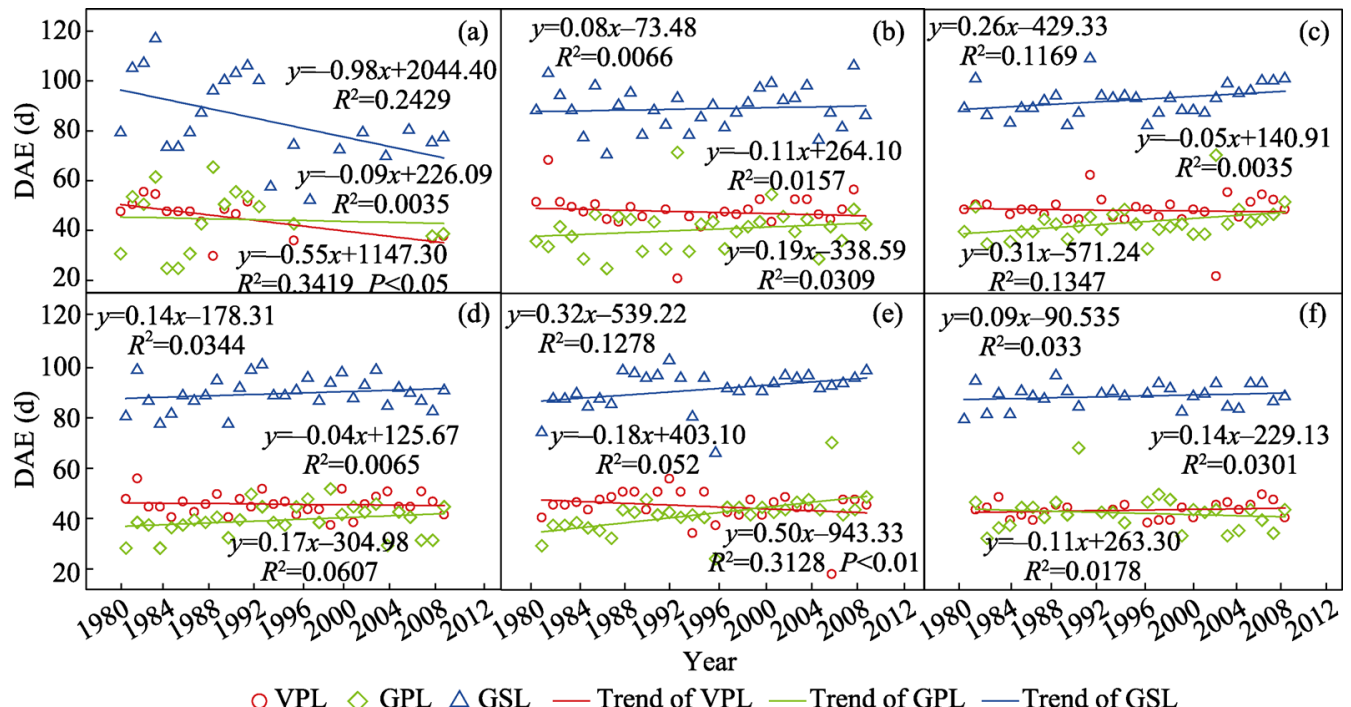

Figure 3 Variations in maize phenological phase in Henan Province

a. LS; b. NY; c. RZ; d. SQ; e. XX; f. ZZ. VPL is the vegetative period length, GPL is the generative period length, and GSL is the entire growing season length, DAE means days after emergence

\subsection{Correlation analysis}

We analyzed the correlation of growing season length (GSL) with key climate factors including average temperature, precipitation, sunshine duration and GDD in Henan. Results showed that average temperature had a significant negative correlation with GSL, and the correlation coefficient was -0.26 (Figure $4 a$ ). However, precipitation, sunshine duration and GDD had positive correlation with GSL and the correlation coefficients were $0.21,0.38$ and 0.78 , respectively (Figures $4 b-4 d$ ). 

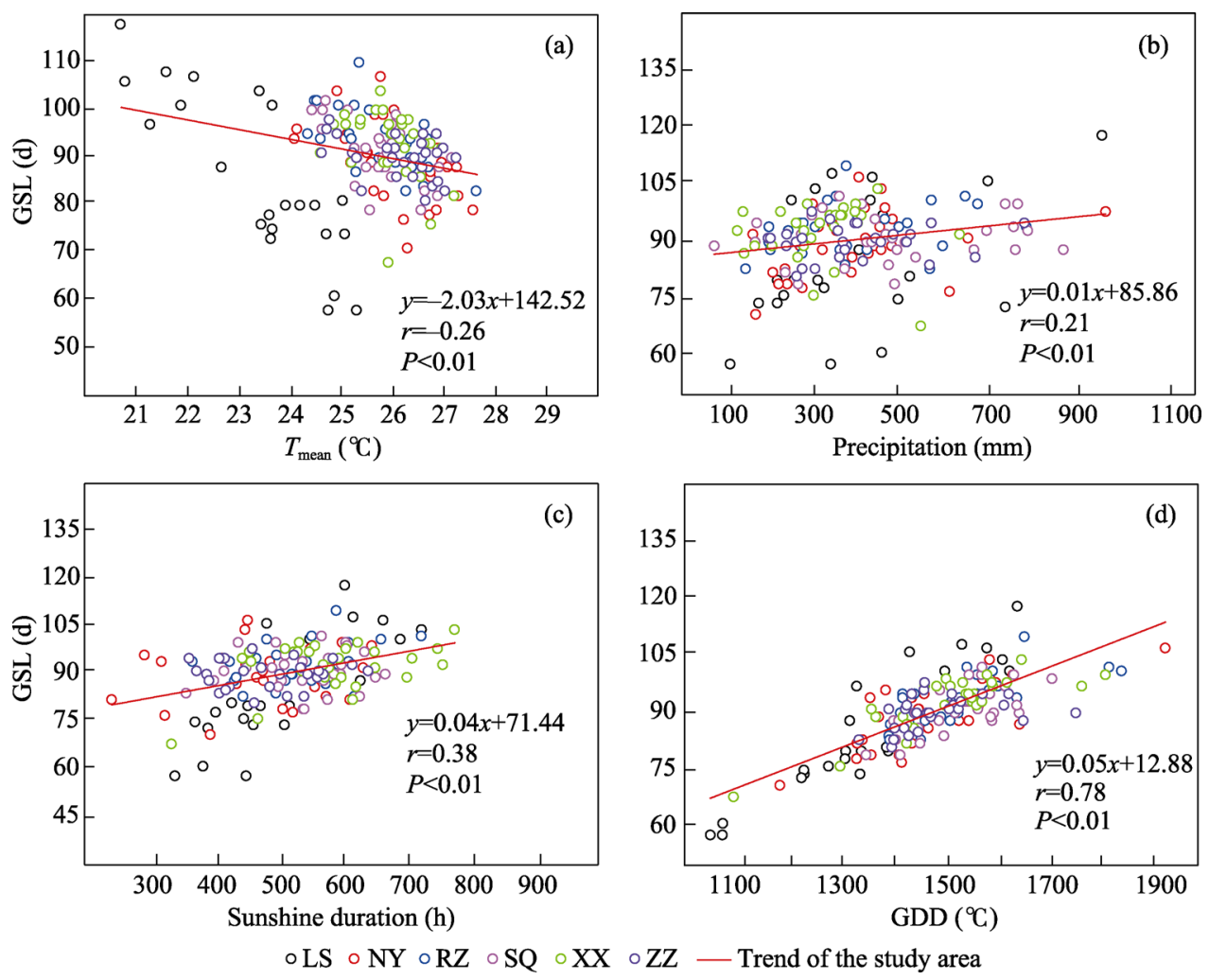

Figure 4 Correlation analysis between key climate factors and maize growing season length

\subsection{Sensitivity analysis}

The sensitivity of maize growing season length to climate factors varied. Responses of GSL at the same site to different climate factors changes were also different. The response of GSL to temperature change was negative. Four of the six selected sites reached significance level. The GSL at LS, NY, RZ, SQ, XX and ZZ was shortened by $10 \mathrm{~d}, 4.7 \mathrm{~d}, 5.0 \mathrm{~d}, 5.5 \mathrm{~d}, 4.0 \mathrm{~d}$ and $3.2 \mathrm{~d}$, respectively when average temperature rose by $1^{\circ} \mathrm{C}$ (Figure $5 \mathrm{a}$ ). Compared with the sensitivity to temperature, the sensitivity of GSL to precipitation at each site was lower. Only LS and NY showed moderate sensitivity levels $(p<0.05)$. The GSL was prolonged by $0.04 \mathrm{~d}$ and $0.02 \mathrm{~d}$, respectively, when precipitation increased by $1 \mathrm{~mm}$ at these two sites. But at XX, the GSL was shortened by $0.001 \mathrm{~d}$ when precipitation increased by $1 \mathrm{~mm}$ (Figure $5 \mathrm{~b}$ ). The sensitivity of GSL to sunshine duration at each site was also different. Sensitivities at LS and XX were the highest, with GSL of maize being prolonged by $0.13 \mathrm{~d}$ and $0.03 \mathrm{~d}$ when the sunshine duration increased by $1 \mathrm{~h}$, respectively (Figure 5c). Sensitivity of GSL to GDD at each site was significant $(p<0.05)$. As GDD increased by $1{ }^{\circ} \mathrm{C}$, the GSL of different sites was prolonged by $0.09 \mathrm{~d}, 0.05 \mathrm{~d}, 0.04 \mathrm{~d}, 0.05 \mathrm{~d}, 0.05 \mathrm{~d}$ and $0.02 \mathrm{~d}$ respectively (Figure $5 \mathrm{~d}$ ). At all of the six sites, responses of GSL at LS to all climate factors reached the significance level. The sensitivities of GSL were $-10 \mathrm{~d}, 0.04 \mathrm{~d}, 0.13 \mathrm{~d}$ and 0.09 , respectively, as average temperature, sunshine duration and GDD increased by one unit. 

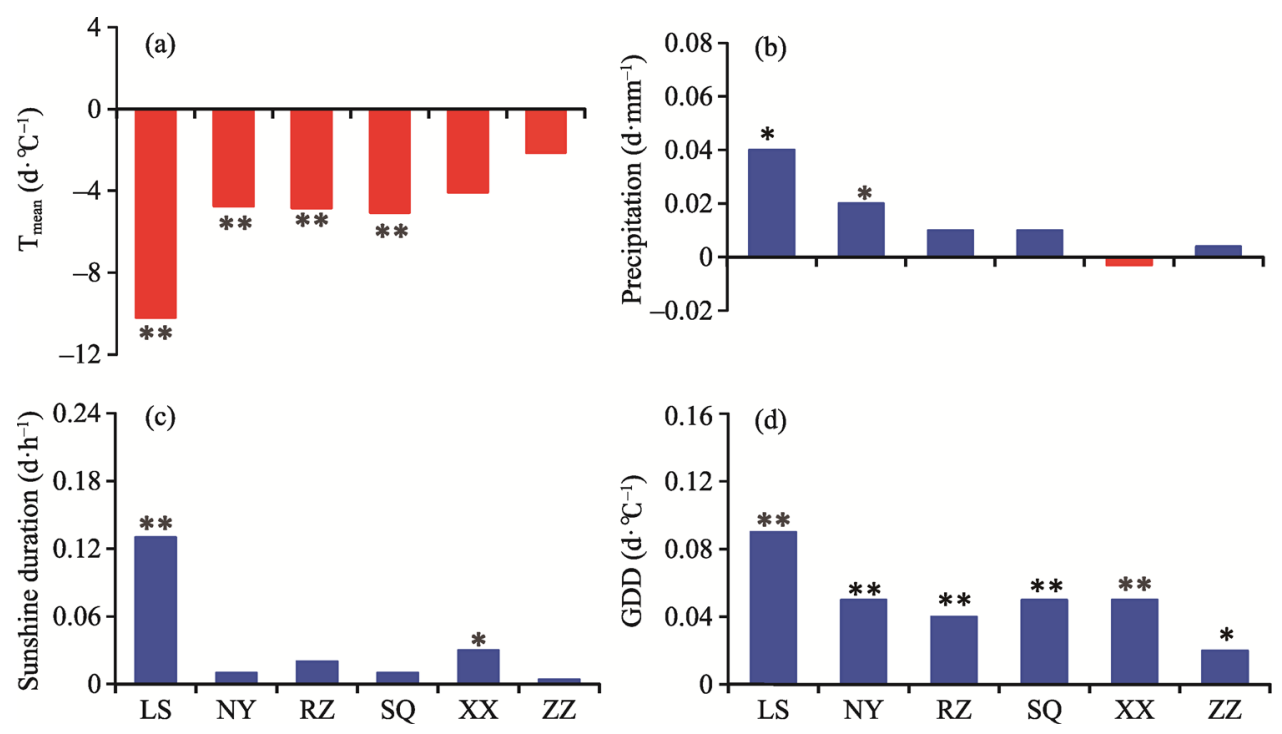

Figure 5 Sensitivity analysis of maize phenological changes in climate factors

\section{Discussion}

\subsection{Climate change impacts on maize phenology}

In this study, detailed and long time series climate and observed phonological data were used to analyze the maize phenological variation and its sensitivity to key climate factors change. Our results indicated that the temperature, precipitation and GDD increased during maize growing season. Meanwhile, the sunshine duration of all sites showed a decreasing trend and LS was the most significant one. The possible reason was air humidity and air pollution caused by human activities in the northern and central parts of Henan. The high humidity and pollution caused an increase in light fog or haze (Zhao et al., 2010), and reduced the visibility of atmosphere. Li et al. (2012) studied the agricultural climatic resources change of summer maize growth period in Henan. He found that the precipitation increased from 1961 to 2008, and the tendency trend was positive in most parts of central, eastern and southern Henan. The changing trend of sunshine duration from 1961 to 2008 also declined and the spatial differences were significant among these years.

Under the background of climate change, VPL in Henan was shortened, but the GPL and GSL were extended during the past 29 years. The correlation coefficient between GDD and GSL was the highest, while the correlation coefficient between precipitation and GSL was the lowest, due to the higher requirements for precipitation and temperature during each physical growth stage of maize. The increase of precipitation delayed some phenological stages. Conversely, persistent droughts advanced the dates of flowering, fruiting and defoliation (Chang and Zhang, 2011). Meng et al. (2015) also found that the maize growing season increased in the North China Plain from 1981 to 2009 and had significant correlation with climate factors. The VPL was prone to drought, which slowed the plants growth and led to a significant delay in the maize growing season (Dou and Yu, 2014; Song et al., 2016). Although the overall trend of maize phenology was advanced and shortened, SOD was pro- 
longed by farmers to adapt to the whole advanced growing season. It can also be found that the maize phenological trends of LS were very similar to that of the whole region, because LS had the highest elevation among the six sites. The phenological fluctuations of LS were much larger than those of the other sites. Overall the MAD was advanced by $0.4 \mathrm{~d} \cdot 10 \mathrm{a}^{-1}$, the amplitudes of the delay in MAD at the other sites were less than the increase at LS. This can explain the main reason why the overall tendency of MAD was advanced. The variations index of generative growth phenology of crops was obviously greater than that of the vegetative growth phenology (Wu et al., 2009).

\subsection{Sensitivities of maize phenological responses to climate change}

Generally, the sensitivities of maize phenology to precipitation, sunshine duration, GDD and the average temperature increased during the maize growing season. But the spatial differences also existed at different sites as the GDD requirements were different (Hou et al., 2014). This is mainly because the spatial and temporal variations of precipitation became more complex with the climate warming. Meanwhile, there were also significant differences in the temperature and precipitation changes with the changes of terrain and seasons (Wang et al., 2010). Climate change would cause variations in crop phenology, which could increase the instability of agricultural production as well as the yield fluctuations (Zhang et al., 2016). The same crop in different regions responded differently to changes in climate factors. Many scholars discussed the responses of crop phenological changes to climate changes (Liu et al., 2013). Guo et al. (2015) found that temperature was a key factor which can accelerate crop growth and determine the length of the growing season. Liu et al. (2014), who studied the impacts of temperature and precipitation on the crop planting system in Hebei Province, concluded that climate change reduced the agricultural production level and raised the production cost to a certain extent. At the same time, frequent extreme climate events also increased the loss of agricultural production. The impacts of climate change on maize phenology in Xinjiang of China showed a trend toward earlier sowing dates. It was due to the rising temperature which caused the crops to meet the accumulated temperature demand in advance, making the tasseling date and maturity date tend to advance (Xiao et al., 2015). Maize varieties and changes in plant density would affect the water consumption during the maize growth period and would further affect the phenology and yield (Liu et al., 2012).

The responses of different crop types to climate change were different. Under the background of climate change, the vegetative growth length of winter wheat in Henan was shortened, while the generative growth length was lengthened (Sun et al., 2014). The trend of warming in March and April was obvious, which advanced the seeding date and transplanting date of rice significantly. The length of time from transplanting to earing was significantly extended (Xue et al., 2010). Annual accumulated temperature higher than $10^{\circ} \mathrm{C}$ significantly increased in the North China Plain, but the precipitation decreased. The seeding date of winter wheat was delayed, but the jointing date was advanced and maturity date of winter wheat was delayed in most parts of the province (Yang et al., 2011). Based on our results, we concluded that the regularity in the changes of vegetative growth period and generative growth period of maize in Henan was similar to that of wheat, but there were some differences with rice. 


\subsection{Uncertainties}

Limited by the length of the article and observed data, we mainly discussed the maize phenological variation and the impacts of climate change on it. In addition, the maize phenology was also affected by the cultivar shifts and field management measure changes. With climate warming, the risk of extreme heat wave and precipitation increased, and the high temperature during the vegetative growth period could reduce the maize photosynthetic rate (Wang et al., 2015). All these factors would affect the growth and development of maize and then lead to phenological changes. The influences of extreme climate change, cultivar shifts, planting density, and irrigation and fertilization management on crop phenology should be considered comprehensively in the future to deeply understand the mechanisms of crop phenological responses to climate change.

\section{Conclusions}

Climate trend rate and sensitivities analysis were applied in this study based on long sequence observed phenological data. The average temperature, precipitation, and GDD in maize growing season all showed increasing trends from 1981 to 2009 . The average temperature increased by $0.2^{\circ} \mathrm{C} \cdot 10 \mathrm{a}^{-1}$, the precipitation increased by $30.7 \mathrm{~mm} \cdot 10 \mathrm{a}^{-1}$, and the GDD increased by $51.6^{\circ} \mathrm{C} \cdot 10 \mathrm{a}^{-1}$ while sunshine duration decreased by $28.1 \mathrm{~h} \cdot 10 \mathrm{a}^{-1}$.

The SOD at the whole study area was delayed by $9.0 \mathrm{~d} \cdot 10 \mathrm{a}^{-1}$, while the EMD, TRD, SLD, JOD, TAD, FLD, SID, MRD and MAD of maize were advanced by $0.8 \mathrm{~d}, 0.1 \mathrm{~d}, 0.2 \mathrm{~d}, 1.3 \mathrm{~d}$, $1.7 \mathrm{~d}, 1.3 \mathrm{~d}, 0.8 \mathrm{~d}, 1.6 \mathrm{~d}$ and $0.4 \mathrm{~d}$, respectively. The VPL of maize was shortened by 0.9 $\mathrm{d} \cdot 10 \mathrm{a}^{-1}$ and GPL of maize was lengthened by $1.7 \mathrm{~d} \cdot 10 \mathrm{a}^{-1}$. The GSL was lengthened by 0.4 $\mathrm{d} \cdot 10 \mathrm{a}^{-1}$.

The GSL of maize has a significant negative correlation with average temperature, but a significant positive correlation with precipitation, sunshine duration and GDD with a significance level of $P<0.01$, and the correlation coefficient was $-0.26,0.21,0.38$ and 0.78 , respectively. The GSL at LS, NY, RZ and SQ were shortened by $10 \mathrm{~d}, 4.7 \mathrm{~d}, 5 \mathrm{~d}$ and $5.5 \mathrm{~d}$, respectively, when the average temperature increased by $1{ }^{\circ} \mathrm{C}$ with a significance level of $p<0.01$. Sensitivity to precipitation was lower than to other climate factors at each site, only LS and NY reached the significance level of $p<0.05$. For an increase in $1 \mathrm{~mm}$ of precipitation, GSL at LS and NY was prolonged by $0.04 \mathrm{~d}$ and $0.02 \mathrm{~d}$, respectively. The sensitivity to sunshine duration of LS and XX reached the significance level of $p<0.05$. When sunshine duration increased by $1 \mathrm{~h}$, the GSL of LS and XX was prolonged by $0.13 \mathrm{~d}$ and $0.03 \mathrm{~d}$, respectively. Maize at all the six sites was sensitive to GDD, that is, when GDD increased by 1 ${ }^{\circ} \mathrm{C}$, the GSL of LS, NY, RZ, SQ, XX and ZZ was prolonged by $0.09 \mathrm{~d}, 0.05 \mathrm{~d}, 0.04 \mathrm{~d}, 0.05 \mathrm{~d}$, $0.05 \mathrm{~d}$ and $0.02 \mathrm{~d}$, respectively.

\section{Acknowledgements}

We thank the anonymous reviewers and editors for raising insightful points/comments on the manuscript, and the China Meteorological Administration for providing data support. 


\section{References}

Chang Z F, Zhang J H, 2011. The achievements, problems and growing point on study of plant phenology. Chinese Agricultural Science Bulletin, 27(29): 276-283. (in Chinese)

Dou C Y, Yu J C, Yu X Q, 2014. Effect of short time and continuous drought stress on growth and yield of maize in semi-arid area of western Liaoning. Journal of Jilin Agricultural Sciences, 39(3): 18-21, 58. (in Chinese)

Guo J P, 2015. Advanced in impact of climate change on agricultural production in China. Journal of Applied Meteorological Science, 26(1): 1-11. (in Chinese)

Guo Z X, Zhang X N, Wang Z M et al., 2010. Simulation and variation pattern of vegetation phenology in Northeast China based on remote sensing. Chinese Journal of Ecology, 29(1): 165-172. (in Chinese)

He L, Asseng S, Zhao G et al., 2015. Impacts of recent climate warming, cultivar changes, and crop management on winter wheat phenology across the Loess Plateau of China. Agricultural and Forest Meteorology, 200: 135-143.

Hou P, Liu Y E, Xie R Z et al., 2014. Temporal and spatial variation in accumulated temperature requirement of maize. Field Crops Research, 158: 55-64.

IPCC, 2013. Climate Change 2013: The Physical Science Basis. In: Stocker T F, Qin D, Plattner G-K et al. eds. Contribution of Working Group I to the Fifth Assessment Report of the Intergovernmental Panel on Climate Change. Cambridge, United Kingdom and New York, NY, USA: Cambridge University Press, 1535 pp.

Ji R P, Zhang Y S, Jiang L X et al., 2012. Effect of climate change on maize production in Northeast China. Geographical Research, 31(2): 291-298. (in Chinese)

Li S Y, Fang W S, Ma Z H, 2012. Change of agricultural climate resources in Henan province during summer maize growing season. Journal of Henan Agricultural Sciences, 41(7): 21-26. (in Chinese)

Liu F Y, Xiao S R, Liu H et al., 2014. Research of impacts of climate change on agriculture in Hebei region. Geography and Geo-Information Science, 30(4): 123-126. (in Chinese)

Liu Y J, Tao F L, 2013. Probabilistic change of wheat productivity and water use in China for global mean temperature changes of 1, 2, and $3^{\circ} \mathrm{C}$. Journal of Applied Meteorology and Climatology, 52(1): 114-129.

Liu Z D, Xiao J F, Yu J C et al., 2012. Effects of varieties and planting density on plant traits and water consumption characteristics of spring maize. Transactions of the Chinese Society of Agriculture Engineering, 28(11): 125-131. (in Chinese)

Ma M G, Wang J, Wang X M, 2006. Advance in the inter-annual variability of vegetation and its relation to climate based on remote sensing. Journal of Remote Sensing, 10(3): 421-431.

Ma S X, Churkina G, Trusilova K, 2012. Investigating the impact of climate change on crop phenological events in Europe with a phenology model. International Journal of Biometeorology, 56(4): 749-763.

McMaster G S, Wilhelm W W, 1997. Growing degree-days: One equation, two interpretations. Agricultural and Forest Meteorology, 87: 291-300.

Meng L, Liu X J, Wu D R et al., 2015. Responses of summer maize phenology to climate changes in the North China Plain. Chinese Journal of Agrometeorology, 36(4): 375-382. (in Chinese)

Oteros J, Garcia-Mozo H, Botey R et al., 2015. Variations in cereal crop phenology in Spain over last twenty-six years (1986-2012). Climatic Change, 130: 545-558.

Puangbut D, Jogloy S, Vorasoot N et al., 2015. Responses of growth, physiological traits and tuber yield in Helianthus tuberosus to seasonal variations under tropical area. Scientia Horticulturae, 195: 108-115.

Ren L L, Yin S Y, 2013. Temperature changes and its impacts on agriculture in the upper reaches of Hanjiang River in southern Shaanxi. Chinese Journal of Agrometeorology, 34(3): 272-277. (in Chinese)

Schleip C, Rais A, Menzel A, 2009. Bayesian analysis of temperature sensitivity of plant phenology in Germany. Agricultural and Forest Meteorology, 149(10): 1699-1708.

Song L B, Yao N, Feng H et al., 2016. Effects of water stresses at different growth stages on development and yields of summer maize in arid region. Journal of Maize Sciences, 24(1): 63-73. (in Chinese)

Sun Q, Huang Y, Ji X J et al., 2014. Characteristic of winter wheat cultivar shift in Henan province under climate 
change. Progressus Inquisitiones de Mutatione Climatis, 10(4): 282-288. (in Chinese)

Tao F L, Zhang Z, Xiao D P et al., 2014. Responses of wheat growth and yield to climate change in different climate zones of China, 1981-2009. Agricultural and Forest Meteorology, 189/190: 91-104.

Wang B, Liu D L, Asseng S et al., 2015. Impact of climate change on wheat flowering time in eastern Australia. Agricultural and Forest Meteorology, 209/210: 11-21.

Wang C Y, He J F, Wu J H, 2010. Study of climate factor effect on summer maize growth and development countermeasures in the southern Henan province. Journal of Shaanxi Agricultural Science, (4): 57-59. (in Chinese)

Wang Y P, Yin X X, Hou Q et al., 2016. Influence of climate on corn and soybean in Eastern Da Hinggan Mountains over the last 30 years. Research of Soil and Water Conservation, 23(4): 326-337. (in Chinese)

Wang Z B, Wang M, Yin X G, et al., 2015. Spatiotemporal characteristics of heat and rainfall changes in summer maize season under climate change in the North China Plain. Chinese Journal of Eco-Agriculture, 23(4): 473-481. (in Chinese)

Wu R J, Zheng Y F, Zhao G Q et al., 2009. Spring phenophase changes of dominant plants in Zhengzhou and their responses to air temperature change. Chinese Journal of Ecology, 28(6): 1049-1054. (in Chinese)

Xiao D P, Qi Y Q, Wang R D et al., 2015. Changes in phenology and climate conditions of wheat and maize in Xinjiang during 1981-2009. Agricultural Research in the Arid Areas, 33(6): 190-202. (in Chinese)

Xue C Y, Liu R H, Wu Q, 2010. Effect of climate warming on rice growing stages in Xinyang. Chinese Journal of Agrometeorology, 31(3): 353-357. (in Chinese)

Yang F, Yao Z F, Song J et al., 2012. Temporal and spatial changes characteristics of the agricultural meteorological factors and crops growth stages in Songnen Plain. Chinese Journal of Agrometeorology, 33(1): 18-26. (in Chinese)

Yang J Y, Mei X R, Liu Q et al., 2011. Variations of winter wheat growth stages under climate changes in northern China. Chinese Journal of Plant Ecology, 35(6): 623-631. (in Chinese)

Zhang X R, Wang C J, Lei W, 2016. Influence of climate change on the agricultural production research of Baoji. Shaanxi Journal of Agricultural Sciences, 62(1): 87-91. (in Chinese)

Zhao D, Luo Y, Gao G et al., 2010. Long-term changes and essential climatic characteristics of sunshine duration over China during 1961-2007. Resources Science, 32(4): 701-711. (in Chinese)

Zhu K Z, Wan M W, 1973. Phenology. Beijing: Science Press, 1-131. (in Chinese) 